Article

\title{
Evaluation of Cross-Sectional Root Canal Shape and Presentation of New Classification of Its Changes Using Cone-Beam Computed Tomography Scanning
}

\author{
Svetlana Razumova, Anzhela Brago, Ammar Howijieh, Haydar Barakat *, Yuliya Kozlova \\ and Malina Baykulova \\ Department of Propaedeutic of Dental Diseases, Medical Institute, Peoples' Friendship University of \\ Russia (RUDN University), 117198 Moscow, Russia; razumova-sn@rudn.ru (S.R.); brago-as@rudn.ru (A.B.); \\ 1042165091@rudn.ru (A.H.); kozlova-yus@rudn.ru (Y.K.); baykulova@rudn.ru (M.B.) \\ * Correspondence: barakat-kh@rudn.ru; Tel.: +7-(926)-642-6925
}

Received: 7 June 2020; Accepted: 26 June 2020; Published: 29 June 2020

\begin{abstract}
The root canal system is considering the most important factor in endodontic treatment, due to the complexity of its anatomy and morphology. The aim of this study was to evaluate the cross-sectional root canal shape in three thirds (coronal, middle, apical) in different age groups using cone-beam computed tomography scanning ( $\mathrm{CBCT}$ ) and to present a new classification for root canal shape changes. This cross-sectional study included $300 \mathrm{CBCT}$ scans for patient aged 20-70, and these scans were evaluated to study the morphology of the cross-sectional root canal shape in coronal, middle, and apical thirds among three age groups, namely the young (20-44), middle (45-59), and elderly (60-70). The root canal shape was classified as round, oval, long oval, and ribbon (with or without isthmus). The cross-sectional root canal shape was identified in two groups: canals with an unchanging (constant) shape and canals with changing shape. In turn, in canals with changing shape, the change could be identified in the region of the middle or apical thirds of the canal. The results showed that root canal shape changes in two cases: (1) the presence of one or more canals in the root (with or without isthmus between them), and (2) with age, as it was observed that the cross-sectional shape of the root canal becomes round in the apical third with age. A new classification of the changes of root canal shape in three thirds (coronal, middle, apical) was presented in this study.
\end{abstract}

Keywords: classification; cone-beam computed tomography; cross-sectional shape; endodontic treatment; root canal anatomy

\section{Introduction}

Successful endodontic treatment depends on major factors, such as the anatomy and morphology of the root canal system, the disinfection of the root canal, and a good sealing. Among these factors, the root canal system is considered the first issue which should be known precisely due to the complexity of its anatomy and morphology. This system varies among populations even in individuals in the same population, the variations in root canal morphology are still a major issue for endodontists [1-3]. Knowledge of root canal morphology is important for clinicians to master therapeutic techniques and clinical outcomes will be improved. Knowing the root canal system means to know the number of roots and canals, the canals configuration and cross-sectional shape.

The root canals could have various cross-sectional shapes, including round, oval, long oval, ribbon ones C-shaped, conical-pyramidal, eight-shaped, trapezoidal, or drop-shaped [4,5]. In the literature, the authors have defined the canal shapes in the coronal third of the root canal, as round, oval, round oval, 
ribbon, irregular and C-shaped canals [6-8]. Ribbon canals (that contain isthmus between the canals) were classified by many authors such as Kim and Hsu [9], Kim and Pécora [10], and Teixeira [11]. Several studies analyzed the presence of isthmus between canals especially in the molar region [12-15]. Some authors have defined the ribbon shapes (with or without isthmus) in the apical third and it was observed that the root canal shape in the apical third could differ from the other thirds. The root canal changes its shape during its course to apex, and this affects the canal instrumentation. In addition, the variations in the geometry of the cross-sectional root canal shape before forming and cleaning have a great influence on the changes that occur during root canal preparation and depend on the preparation methods. The preparation and treatment of the apical third of the root canal and apical foramen has been the subject of numerous studies [16-18].

In most of the studies, authors have used micro- computed tomography to study the morphology of the root canal system, this method is effective and helpful especially when studying anatomical structures [19]. Also, another technique is used to study the anatomical and morphological structures of the root canal system is cone-beam computed tomography (CBCT) which induces high-resolution, three-dimensional scans [20].

Till now, the root canal shape was studied in one third, coronal or apical, but this shape changes and this change is so significant in endodontic treatment, that is why the aim of this research was to study the cross sectional root canal shape and its changes in three thirds (coronal, middle, apical) in different age groups using cone-beam computed tomography scanning and present a new classification of root canal shape changes.

\section{Materials and Methods}

This cross-sectional study was conducted to evaluate the cross-sectional root canal shape among different age groups in the period between November 2018 and March 2020.

Sample size was determined according to other publishing studies, namely those of $\mathrm{Hu}$ et al. [21,22], and taking into account the three age groups, three hundred CBCT scans for 300 subjects, aged (20-70) years, were included in this study. The study was conducted in accordance with the Helsinki Declaration of 1975, as revised in 2000, and was approved by the ethical committee of the Peoples' Friendship University of Russia University (Protocol 6 at 21.02.2019). The study was conducted in university clinical clinics and radiologic diagnostic centers for three-dimensional radiological scanning in Moscow. Subjects attending the university clinics for endodontic therapeutic purposes were asked to participate in this study and to do a CBCT scan. After collecting the sample, subjects were divided into three age groups by 100 subjects for each: young age (20-44) years, middle age (45-59) years, and elderly (60-70). Written consent was obtained from the subjects participating in the study.

The CBCT scans were taken using a 3D eXam (KaVo, Biberach, Germany) with standard exposure settings ( $23 \mathrm{~cm} \times 17 \mathrm{~cm}$ field of view, $0.3 \mathrm{~mm}$ voxel size, $110 \mathrm{kv}, 1.6-20 \mathrm{~s})$ and were viewed by three examiners in a semi-dark room using I-CAT viewer software (version 10, Hatfield, UK).

The morphology of the cross-sectional root canal shape was studied on healthy teeth in axial slices in three thirds of the root canal, coronal at $2 \mathrm{~mm}$ level down the root canal orifice, middle of the root canal, and apical at $2 \mathrm{~mm}$ level of the apex in each age group.

The root canal shape was recorded according to this classification: round, oval, long oval, and ribbon.

The criteria for root canal shape classification were as follows: the round canal was defined when the mesio-distal diameter of the root canal was equal to the bucco-lingual/palatal diameter. The oval and long oval canals were determined when the bucco-lingual/palatal diameter was two to four time greater than the mesio-distal diameter of the root canal. The ribbon canal shape (that contain isthmus) was studied according to Kim's Classification [10] as follow:

- Type I: Incomplete isthmus between two canals.

- Type II: A complete isthmus between two canals.

- Type III: A short, complete isthmus between two canals. 
- Type IV: A complete or incomplete isthmus between three or more canals.

- Type V: two or three canals without obvious connection between them.

The changes in root canal shape recorded in coronal, middle and apical thirds of the root canal system.

Statistical analysis: IBM SPSS Statistics v 22.0 licensed package (IBM, Chicago, IL, USA) was used for statistical processing of the study data. The method of descriptive statistics used for statistical processing of the received data. To compare the new classification of root canal shape among age groups, the Kruskal-Wallis test and Mann-Whitney U test were used. Statistical significance was set at 0.05 .

\section{Results}

Three hundred CBCT scans were analyzed for three age groups. In total: for maxillary teeth, 378 central incisors, 392 lateral incisors, 357 canines, 310 first premolars, 300 second premolars, 261 first molars, and 250 second molars were studied. Meanwhile, for mandibular teeth, 481 central incisors, 475 lateral incisors, 456 canines, 347 first premolars, 300 second premolars, 250 first molars, and 248 second molars were studied.

The cross-sectional root canal shape was identified in two groups: canals with an unchanging (constant) shape and canals with changing shape. In turn, in canals with changing shape, the change could be identified in the region of the middle or apical thirds of the canal (Table 1).

Table 1. Classification of cross-sectional root canal shape according to teeth.

\begin{tabular}{|c|c|c|c|}
\hline \multirow{3}{*}{ No Change } & \multicolumn{3}{|c|}{ Cross-Sectional Root Canal Shape } \\
\hline & \multicolumn{3}{|c|}{ Change } \\
\hline & In The Middle Third & In the Apical Third & In the Middle and Apical Thirds \\
\hline Anterior teeth & Mandibular incisors & $\begin{array}{l}\text { Mandibular premolars } \\
\text { and one-rooted maxillary premolars }\end{array}$ & $\begin{array}{l}\text { Mandibular premolars } \\
\text { and one-rooted maxillary premolars }\end{array}$ \\
\hline $\begin{array}{l}\text { Two-rooted maxillary } \\
\text { premolars }\end{array}$ & $\begin{array}{l}\text { One-rooted maxillary } \\
\text { premolars }\end{array}$ & Mesio-buccal canals maxillary molars & $\begin{array}{c}\text { Mesio-buccal canals maxillary } \\
\text { molars }\end{array}$ \\
\hline $\begin{array}{l}\text { Distal and palatal canals } \\
\text { maxillary molars }\end{array}$ & Mandibular premolars & $\begin{array}{l}\text { Mesial and distal canals mandibular } \\
\text { molars }\end{array}$ & $\begin{array}{l}\text { Mesial and distal canals mandibular } \\
\text { molars }\end{array}$ \\
\hline
\end{tabular}

According to the obtained results, this study suggested a new classification of the changes in cross-sectional root canal shape depending on the third, where the shape changes, and this classification was defined in Table 2.

Table 2. Classification of changes of cross-sectional root canal shape.

\begin{tabular}{cc}
\hline Types & Description \\
\hline Type I & Un-changed cross-sectional root canal shape from coronal to apical third \\
Type II & Changed cross-sectional root canal shape in the middle third \\
Type III & Changed cross-sectional root canal shape in the middle and apical thirds \\
Type IV & Changed cross-sectional root canal shape in the apical third \\
\hline
\end{tabular}

\subsection{Anterior Teeth}

For maxillary anterior teeth: the cross-sectional root canal shape was defined to be round for incisors and oval for canines in the three thirds in each age group. No statistical differences were observed for this group of teeth (Figure 1). The significant difference was observed in the diameter of the root canal in elderly group which was observed to be smaller than other age groups $(\mathrm{P}<0.05)$. 


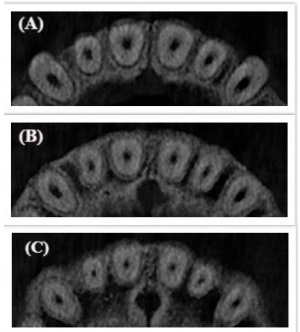

Figure 1. Unchanged cross-sectional root canal shape for maxillary anterior teeth (A) Coronal; (B) Middle; (C) Apical.

For mandibular anterior teeth, the cross-sectional root canal shape was defined to be oval or long oval for incisors in the three thirds in $95 \%$ at the young age. In $5 \%$, the cross-sectional root canal shape was changed in the middle third to ribbon type I and in the apex re-changed to long-oval. For canines, the shape of the root canal was defined to be oval in three thirds in $96 \%$. In $4 \%$, the root canal shape changed in the middle third (Figure 2).

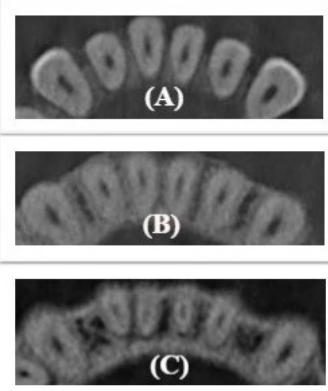

Figure 2. Changed cross-sectional root canal shape for mandibular anterior teeth in the middle third.

(A) Coronal; (B) Middle; (C) Apical.

\subsection{Premolars Teeth}

For two-rooted maxillary premolars, the root canal shape was round in the three thirds in each root in each age group. For one-rooted maxillary and mandibular premolars, it was observed changes in root canal shape in coronal, middle and apical layers. In some cases, the shape changed from oval or round to ribbon or from oval to round in the apical third (Figure 3 ). The changes were observed more in the middle and apical third of the premolars in each age groups.
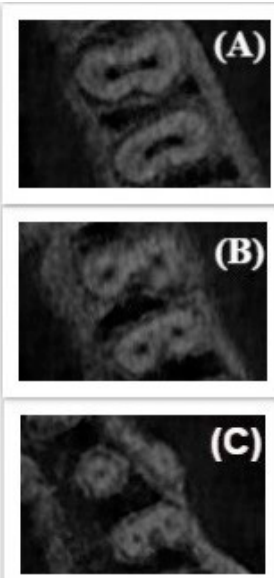

Figure 3. Changed cross-sectional root canal shape for maxillary second premolar from oval in the coronal third to ribbon in the middle and apical third ((A): refers to coronal third, (B): middle third, (C): apical third of root canal). 


\subsection{Molars Teeth}

For maxillary molars, the following regularity of root canals shape was established as follow: the palatal and distobuccal canals usually have a round or oval shape that did not change in the three thirds in most cases. The mesiobuccal canals had a variable structure: the cross-sectional shape could change from oval in the coronal third to ribbon especially in the apical third (Figure 4).

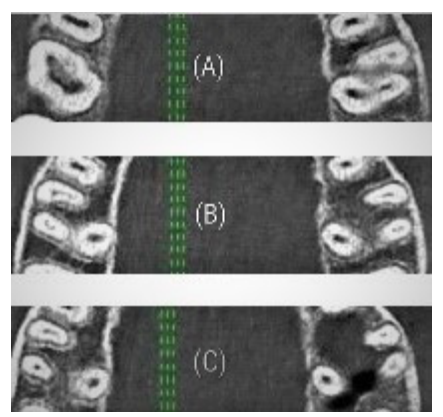

Figure 4. Changed cross-sectional root canal shape for maxillary first molar from ribbon shape in the coronal third to oval in the middle and apical thirds for MB root. ((A): refers to coronal third, (B): middle third, (C): apical third of root canal).

For mandibular molars, it was observed a variability in the cross-sectional root canals shape for both the distal and mesial roots.

More often the shape changed in the young and middle age group. For the elderly age group, the unchanging shape of the canals in the mesial and distal roots was most characteristic (Figure 5).

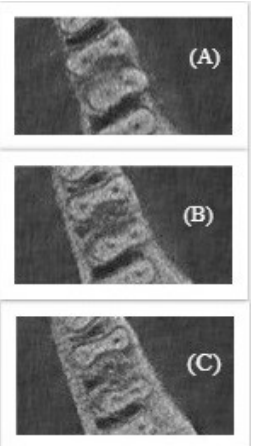

Figure 5. Changed cross-sectional root canal shape for mandibular first molar from ribbon shape type I in the coronal third to ribbon type 5 in the apical third for mesial root. ((A): refers to coronal third, (B): middle third, (C): apical third of root canal).

Tables 3-5 represent the new classification of cross-sectional root canal shape changes among age groups.

Table 3. Changes of cross-sectional root canal shape in young age group.

\begin{tabular}{cccccc}
\hline Young Group & Root & Type I & Type II & Type III & Type IV \\
\hline Maxillary anterior teeth & One-rooted & $100 \%$ & 0 & 0 & 0 \\
Maxillary premolars & Two-rooted & $100 \%$ & 0 & 0 & 0 \\
& One-rooted & $60 \%$ & $13 \%$ & $17 \%$ & $10 \%$ \\
Maxillary molars & $\mathrm{MB}$ & $5 \%$ & $6 \%$ & $49 \%$ & $40 \%$ \\
& $\mathrm{DB}$ & $75 \%$ & 0 & $15 \%$ & $10 \%$ \\
Mandibular anterior teeth & $\mathrm{P}$ & $88 \%$ & 0 & $4 \%$ & $8 \%$ \\
Mandibular premolars & One-rooted & $95 \%$ & $5 \%$ & 0 & 0 \\
Mandibular molars & One-rooted & $36 \%$ & $8 \%$ & $40 \%$ & $16 \%$ \\
& $\mathrm{M}$ & $68 \%$ & 0 & $12 \%$ & $20 \%$ \\
& $\mathrm{D}$ & $46 \%$ & 0 & $28 \%$ & $26 \%$ \\
\hline
\end{tabular}


Table 4. Changes of cross-sectional root canal shape in middle age group.

\begin{tabular}{cccccc}
\hline Middle Group & Root & Type I & Type II & Type III & Type IV \\
\hline Maxillary anterior teeth & One-rooted & $100 \%$ & 0 & 0 & 0 \\
Maxillary premolars & Two-rooted & $100 \%$ & 0 & 0 & 0 \\
& One-rooted & $49 \%$ & $4 \%$ & $34 \%$ & $13 \%$ \\
Maxillary molars & $\mathrm{MB}$ & $3 \%$ & $10 \%$ & $46 \%$ & $41 \%$ \\
& $\mathrm{DB}$ & $71 \%$ & 0 & $11 \%$ & $18 \%$ \\
Mandibular anterior teeth & $\mathrm{P}$ & $77 \%$ & 0 & $13 \%$ & $10 \%$ \\
Mandibular premolars & One-rooted & $96 \%$ & $3 \%$ & $1 \%$ & 0 \\
Mandibular molars & One-rooted & $53 \%$ & $2 \%$ & $31 \%$ & $14 \%$ \\
& $\mathrm{M}$ & $58 \%$ & 0 & $24 \%$ & $18 \%$ \\
\hline
\end{tabular}

Table 5. Changes of cross-sectional root canal shape in elderly age group.

\begin{tabular}{cccccc}
\hline Elderly Group & Root & Type I & Type II & Type III & Type IV \\
\hline Maxillary anterior teeth & One-rooted & $100 \%$ & 0 & 0 & 0 \\
Maxillary premolars & Two-rooted & $100 \%$ & 0 & 0 & 0 \\
& One-rooted & $56 \%$ & $9 \%$ & $24 \%$ & $11 \%$ \\
Maxillary molars & $\mathrm{MB}$ & $6 \%$ & $7 \%$ & $39 \%$ & $48 \%$ \\
& $\mathrm{DB}$ & $76 \%$ & 0 & $9 \%$ & $15 \%$ \\
Mandibular anterior teeth & $\mathrm{P}$ & $84 \%$ & 0 & $9 \%$ & $7 \%$ \\
Mandibular premolars & One-rooted & $93 \%$ & $5 \%$ & $2 \%$ & 0 \\
Mandibular molars & One-rooted & $43 \%$ & $5 \%$ & $24 \%$ & $28 \%$ \\
& $\mathrm{M}$ & $64 \%$ & 0 & $21 \%$ & $15 \%$ \\
\hline
\end{tabular}

When comparing the cross-sectional root canal shape changes among the study age groups, it was observed a significant difference in premolar and molar teeth in middle and elderly group $(\mathrm{P}<0.05)$. Type III of the new classification was higher in maxillary premolars in the middle age group and Type IV was higher in mesio-buccal canals in elderly group.

\section{Discussion}

The cross-sectional root canal shape varies, it could be round, oval, long oval or ribbon. This was the first study to analyze the cross-sectional root canal shape and its changes during its course to apex among different age groups. This study has demonstrated the changes in the root canal cross-sectional shape between the coronal, middle, and apical thirds among different age groups. The results of this study showed that root canal shape changes in two cases: (1) the presence of one or more canals in the root (with or without isthmus between them), (2) with age, as it was observed that the cross-sectional shape of the root canal becomes round with age in the apical third. This study described four types of root canal shape changes as follows: type I: un-changed cross-sectional root canal shape from coronal to apical third; type II: changed cross-sectional root canal shape in the middle third; type III: changed cross-sectional root canal shape in the middle and apical thirds; type IV: changed cross-sectional root canal shape in the apical third. This is the main difference of our classification from other classifications, which described the canal shape just in coronal third. This study revealed that that the most common change in cross-sectional root canal shape was among premolars, in which the shape changes from oval in the coronal third to round in the apical third. The second common change was observed in mesial roots in mandibular molars, in which the shape changed from ribbon type I in the coronal third to ribbon type $\mathrm{V}$ in the middle and apical third, in some cases the it turned to oval in the apical third.

The important aspects of root canal shape can be explained as follow: (1) the presence of different variants of root canal morphology require different methods of preparation and obturation, (2) non-round canals can't be enlarged to round without perforation which weakens the root, (3) the preparation of oval or ribbon canals cannot be prepared to a round shape, which created by 
rotating tools, and therefore, parts of them remain unprepared, which could potentially lead to failure of endodontic treatment, (4) the taper of endodontic instruments should match the root canal taper, because if the taper does not match, the purpose of the mechanical preparation will not be achieved. While the instrument has excessive taper, this will lead to excessive removal of the dentin and weakening of the tooth structure, and at that time, the instrument will not be able to effectively clean the apical third of the canal [18]. While recently, new rotary instruments such as (SAF, XP-endo Shaper, and TRU Shape) were used in the preparation oval root canals and presented a higher percent of touched walls without excessive removing of dentine, which is so effective in endodontic treatment $[17,23,24]$.

Mechanical preparation of root canals can be performed using hand tools or rotary instrument. Cleaning and shaping the entire wall of the main canal depends on a number of factors, such as canal morphology, canal wall thickness, canal taper, type of tool used and its size. Among all factors, the root canal morphology can be considered the most important since all other factors, like the choice of preparation technique and the choice of instrument depend on and are determined by the shape of the canal. It is also very difficult to adequately clean the canals only with tools, because most often tools create a round canal shape, leaving isthmuses, narrowing unprepared and filled with debris, which increases the importance of choosing the right solution for irrigation with a sufficient volume and method of irrigation $[18,25]$.

A few studies have evaluated the root canal shape, as Mehrvarzfar et al. studied the ribbon shape in the apical third according to Kim and Pécora classification in the mesial roots of mandibular molars, it was observed at $6 \mathrm{~mm}$ of the apex type I in $8.3 \%$, type II $40 \%$, type III $8.3 \%$, type IV $18.3 \%$, and type V $25 \%$. At $4 \mathrm{~mm}$ of the apex the prevalence of types I, II, III, IV, and V was $11.7 \%, 16.7 \%, 15 \%, 10 \%$, and $46.8 \%$, respectively, and at $2 \mathrm{~mm}$ of the apex the prevalence of types I, II, III, IV and V was as follow $30 \%, 10 \%, 5 \%, 3.3 \%$, and $51.7 \%$, respectively [7]. This study demonstrates the change of root canal shape in the apical third, which coincide with the results of our study.

In Brazil, a micro-CT study of Fumes et al. was conducted to study the shape of the canals of the first and second molars in the apical area. For mandibular first molars, a rounded shape was detected in the mesial root in 30\%, oval in 10\%, ribbon in $50 \%$, and irregular in $10 \%$ of cases, and in the distal root a round shape in $30 \%$, oval in $20 \%$, ribbon in $40 \%$, and irregular in $10 \%$ of cases. For the mandibular second molars in the mesial root revealed a round shape in $30 \%$, ribbon in $60 \%$, and irregular in $10 \%$ of cases, and in the distal root, a round shape in $40 \%$, oval in $20 \%$ and ribbon in $40 \%$ of cases. For maxillary first molar, a round shape in $10 \%$, oval in $30 \%$, ribbon in $50 \%$ and irregular in $10 \%$ of cases were revealed in the mesio-buccal root, for the disto-buccal root, an oval shape was observed in $100 \%$ of cases, and in the palatal root round shape was found in $20 \%$ and oval in $80 \%$ of cases. For the maxillary second molars in the mesio-buccal root revealed a rounded shape in $20 \%$, oval in $30 \%$, ribbon in $40 \%$ and irregular in $10 \%$ of cases, in the disto-buccal root revealed an oval shape in $100 \%$ of cases, and in the palatal root a rounded shape in $30 \%$, oval in $70 \%$ of cases [26].

In 2016 (China), Hu et al. [21] studied morphological changes in the root canals of the maxillary first premolar using CBCT in different age groups and found that the morphology of the sections in most age groups was ribbon (48.5\%) and oval (28.2\%). In 2019, the researchers [22] studied the anatomy and morphology of the second maxillary premolar using CBCT and differences with age, and found that in most groups, the ribbon shape was higher in $57.8 \%$ of cases and the oval form in $31.3 \%$. Researchers concluded that with age, the percentage of the round shape gradually increased, while the ribbon and oval shapes decreased, these results are expected, as it is known that the physiological deposition of tertiary dentin along the life of human beings will change the morphology of root canals, resulting in narrowing and rounding.

Kacharaju et al. studied the morphology of the root canals of mandibular premolars in the Malaysian population. The study revealed that in the coronal third, an oval shape was detected in $52 \%$, round in $1 \%$ and irregular in $46 \%$. In the middle third of the canal, the oval shape was detected in $36 \%$ of cases, round in $21 \%$ of cases, irregular in $30 \%$ of cases, ribbon with isthmus in $7 \%$ of cases, and ribbon without isthmus in $6 \%$ of cases. In the apical third, the canal shape changed. In $22 \%$, 
an oval shape was detected, in $37 \%$ it was round, in $25 \%$ it was irregular, in $8 \%$ it was ribbon with an isthmus, and in $8 \%$ it was ribbon without an isthmus [6].

This variability of the root canal shape is important to understand in order to complete the endodontic treatment stage, namely mechanical treatment (preparation of the root canal). The choice of instrument and technique for preparing the canal will determine the effectiveness and correctness of this stage, and therefore a favorable prognosis of treatment.

According to the presented classification, the most changes were observed in the middle and apical thirds of the root canal in each age group, and using this classification help the clinicians chose the proper instrument for endodontic treatment as using these instruments (SAF, XP-endo Shaper, and TRU Shape) for preparing oval canals.

\section{Conclusions}

Within the limits of this study, the results showed that the cross-sectional root canal shape varies in different thirds of the root canal and among age groups, these variations was presented in a new classification explained the changes in root canal shape in the three thirds. These variations should be taken into consideration while performing endodontic treatment to choose the right technique for cleaning and shaping.

Author Contributions: S.R.: Conceptualization, Methodology, Software, Writing-Reviewing and Editing. A.B.: Data curation, Writing-Original draft preparation. A.H.: Resources, Data curation, Investigation, Writing-Reviewing and Editing. H.B.: Visualization, Investigation, Writing-Reviewing and Editing. Y.K.: Supervision. M.B.: Software, Validation. All authors have read and agreed to the published version of the manuscript.

Funding: No funding was received.

Conflicts of Interest: The authors declare that they have no competing interests.

\section{References}

1. Razumova, S.; Brago, A.; Khaskhanova, L.; Howijieh, A.; Barakat, H.; Manvelyan, A. A Cone-Beam Computed Tomography Scanning of the Root Canal System of Permanent Teeth among the Moscow Population. Int. J. Dent. 2018, 2018, 2615746. [CrossRef] [PubMed]

2. Valenti-Obino, F.; Di Nardo, D.; Quero, L.; Miccoli, G.; Gambarini, G.; Testarelli, L.; Galli, M. Symmetry of root and root canal morphology of mandibular incisors: A cone-beam computed tomography study in vivo. J. Clin. Exp. Dent. 2019, 11, 527. [CrossRef] [PubMed]

3. Boschetti, E.; Silva-Sousa, Y.T.C.; Mazzi-Chaves, J.F.; Leoni, G.B.; Versiani, M.A.; Pecora, J.D.; Saquy, P.C.; de Sousa-Neto, M.D. Micro-CT Evaluation of Root and Canal Morphology of Mandibular First Premolars with Radicular Grooves. Braz. Dent. J. 2017, 28, 597-603. [CrossRef]

4. Wu, M.K.; R'oris, A.; Barkis, D.; Wesselink, P.R. Prevalence and extent of long oval canals in the apical third. Oral Surg. Oral Med. Oral Pathol. Oral Radiol. Endod. 2000, 89, 739-743. [CrossRef] [PubMed]

5. Jou, Y.T.; Karabuchak, B.; Levin, J.; Liu, D. Endodontic working width: Current concepts and techniques. Dent. Clin. North. Am. 2004, 48, 323-335. [CrossRef] [PubMed]

6. Kacharaju, K.R.; Hari, P.; Yee, A.; Ngo, J.; Ismail, M.F. Analysis of Mandibular Premolars Root Canal Morphology Using Radiographic and Cross-Sectional Techniques in Malaysian Population. Dent. Hypotheses 2019, 10, 9-14. [CrossRef]

7. Mehrvarzfar, P.; Akhlagi, N.M.; Khodaei, F.; Shojaee, G.; Shirazi, S. Evaluation of isthmus prevalence, location, and types in mesial roots of mandibular molars in the Iranian Population. Dent. Res. J. (Isfahan) 2014, 11, 251-256.

8. Martins, J.N.; Mata, A.; Marques, D.; Anderson, C. Prevalence and Characteristics of the Maxillary C-shaped Molar. J. Endod. 2016, 42, 383-389. [CrossRef] [PubMed]

9. Hsu, Y.; Kim, S. The resected root surface: The issue of canal isthmuses. Dent. Clin. N. Am. 1997, 3, 529-540.

10. Kim, S.; Pecora, G.; Rubinstein, R. Color Atlas of Microsurgery in Endodontics; WB Saunders: Philadelphia, PA, USA, 2001; pp. 125-150. 
11. Teixeira, F.B.; Sano, C.L.; Gomes, B.P.; Zaia, A.A. A preliminary in vitro study of the incidence and position of the root canal isthmus in maxillary and mandibular first molars. Int. Endod. J. 2003, 36, 276-280. [CrossRef] [PubMed]

12. Mohammadzadeh-Akhlaghi, N.; Mehrvarzfar, P.; Hossein, M.; Dds, Z. Incidence, location, and type of isthmus in mandibular second molars among individuals of an Iranian population. J. Oral. Health Oral Epidemiol. 2018, 7, 59-63.

13. Shrestha, S.; Karki, S.; Agrawal, N.; Vikram, M. Prevalence of Different Types of Apical Root Canal Morphology and their Treatment Recommendations in an Institute. J. Nepal. Med. Assoc. 2018, 56, 616-620. [CrossRef]

14. Pécora, J.D.; Estrela, C.; Bueno, M.R.; Porto, O.C.; Alencar, A.H.; Sousa-Neto, M.; de Araújo Estrela, C.R. Detection of Root Canal Isthmuses in Molars by Map-Reading Dynamic using CBCT images. Braz. Dent. J. 2013, 24, 569-574.

15. Uma, C.H.; Ramachandran, S.; Indira, R.; Shankar, P. Canal and isthmus morphology in mandibular incisors - An in vitro study. J. Endod. 2004, 16, 7-11.

16. Peters, O.A.; Peters, C.I.; Schönenberger, K.; Barbakow, F. ProTaper rotary root canal preparation: Effects of canal anatomy on final shape analysed by micro CT. Int. Endod. J. 2003, 36, 86-92. [CrossRef]

17. Lacerda, M.F.; Marceliano-Alves, M.F.; Pérez, A.R.; Provenzano, J.C. Cleaning and shaping oval canals with 3 instrumentation systems: A correlative micro-computed tomographic and histologic study. J. Endod. 2017, 43, 1878-1884. [CrossRef]

18. Sousa-Neto, M.D.; Silva-Sousa, Y.C.; Mazzi-Chaves, J.F.; Teodoro Carvalho, K.K. Root canal preparation using micro-computed tomography analysis: A literature review. Braz. Oral. Res. 2018, 32, 66. [CrossRef] [PubMed]

19. Alkaabi, W.; AlShwaimi, E.; Farooq, I.; Goodis, H.; Chogle, S. A Micro-Computed Tomography Study of the Root Canal Morphology of Mandibular First Premolars in an Emirati Population. Med. Princ. Pract. 2017, 26, 118-124. [CrossRef]

20. Zhu, L.N.; Qian, W.H.; Hong, J. A cone-beam computed tomography study of changes in canal isthmus of maxillary first premolars before and after instrumentation. Shanghai Kou Qiang Yi Xue 2013, 22, 41-45.

21. Hu, R.C.; Cao, L.L.; Xie, W.; Hu, Y.Q. Aging changes of the root canal morphology in maxillary first premolars observed by cone-beam computerized tomography. Zhonghua Kou Qiang Yi Xue Za Zhi 2016, 51, $224-229$. [CrossRef]

22. Hu, R.C.; Xie, W.; Hu, Y.Q.; Piao, Z.G. Root canal anatomy of maxillary second premolars at various ages observed by cone-beam CT. Zhonghua Kou Qiang Yi Xue Za Zhi 2019, 54, 733-738. [CrossRef] [PubMed]

23. Zuolo, M.L.; Zaia, A.A.; Belladonna, F.G.; Silva, E.J.; Souza, E.M.; Versiani, M.A.; Lopes, R.T.; De-Deus, G. Micro-CT assessment of the shaping ability of four root canal instrumentation systems in oval-shaped canals. Int. Endod. J. 2018, 51, 564-571. [CrossRef] [PubMed]

24. Paqué, F.; Peters, O.A. Micro-computed tomography evaluation of the preparation of long oval root canals in mandibular molars with the selfadjusting file. J. Endod. 2011, 37, 517-521.

25. Di Nardo, D.; Gambarini, G.; Miccoli, G.; Di Carlo, S.; Iannarilli, G.; Lauria, G.; Seracchiani, M.; Khrenova, T.; Bossù, M.; Testarelli, L. Sonic vs Ultrasonic activation of sodium hypoclorite for root canal treatments. In vitro assessment of debris removal from main and lateral canals. Giornale Italiano Di Endodonzia 2020, 34, 90-96.

26. Fumes, A.C.; Sousa-Neto, M.D.; Leoni, G.B.; Versiani, M. Root canal morphology of primary molars: A micro-computed tomography study. Eur. Arch. Paediatr. Dent. 2014, 15, 317-326. [CrossRef] [PubMed]

(C) 2020 by the authors. Licensee MDPI, Basel, Switzerland. This article is an open access article distributed under the terms and conditions of the Creative Commons Attribution (CC BY) license (http://creativecommons.org/licenses/by/4.0/). 